\title{
Hydrodynamic cavitation as a treatment process for vessel ballast water management
}

Michael Levey, CEO ${ }^{a}$

aGlobal Advantech Resources Limited, Westpoint House, Prospect Park, Prospect Road, Arnhall Business Park, Westhill, AB32 6FJ, United Kingdom

\section{ABSTRACT}

Global Advantech Resources has identified that hydrodynamic cavitation, a technology it has been harnessing for a number years for completely different, unrelated application, is capable of being utilised as an efficient and cost effective method for ballast water treatment to treat very large pumped water flows within a short period of time.

\section{Introduction and background}

The overriding requirement of the Ballast Water Management Convention (BWMC) is to prevent the transfer of (invasive) species between marine ecosystems through the installation of onboard vessel treatment systems that are able to efficiently treat ballast water to kill/remove aquatic organisms, larvae, etc. Whilst ballast water exchange has been used for many years, it is not as efficient as ballast water treatment in preventing transfers of species between ecosystems.

Owners/operators of large vessels are now facing the problem of how to implement effective and cost efficient water treatment solutions, which comply with the BWMC and are capable of treating the volumes of water for ballasting that are taken on board and discharged within very short timeframes. To illustrate the problem, the tables below shows typical ballast water capacities and pump rates for different classes of seagoing vessel:

Table 1. Typical ballast water capacities and pump rates for different classes of seagoing vessel (larger vessels)

\begin{tabular}{lcc}
\hline Larger vessels & $\begin{array}{c}\text { Typical Ballast Capacity } \\
\text { (m3) }\end{array}$ & $\begin{array}{c}\text { Typical Intake/Discharge } \\
\text { Pump Rate (m3/hr) }\end{array}$ \\
\hline Tankers & 95,000 & 5,800 \\
ULCC & 90,000 & 5,000 \\
VLCC & 54,000 & 3,125 \\
Suezmax & 31,000 & 2,500 \\
Aframax & 31,000 & 2,500 \\
Handymax & 6,500 & 1,100 \\
Handy & & \\
& & 3,000 \\
Bulk Carriers & 65,000 & 1,800 \\
Capesize & 35,000 & 1,300 \\
Panamax & 18,000 & \\
Handy & & \\
\hline
\end{tabular}


Table 2. Typical ballast water capacities and pump rates for different classes of seagoing vessel (smaller vessels)

\begin{tabular}{lcc}
\hline Smaller vessels & $\begin{array}{c}\text { Typical Ballast Capacity } \\
(\mathbf{m} 3)\end{array}$ & $\begin{array}{c}\text { Typical Intake/Discharge } \\
\text { Pump Rate (m3/hr) }\end{array}$ \\
\hline Containerships & & 750 \\
Post-Panamax & 20,000 & 500 \\
Sub-Panamax & 14,000 & 500 \\
Panamax & 17,000 & 400 \\
Feedermax & 3,500 & 400 \\
Handy & 8,000 & 250 \\
Feeder & 3,000 & \\
& & 600 \\
Other vessels & & 400 \\
Chemical Carrier & 11,000 & 400 \\
General Cargo & 4,500 & 400 \\
RO/RO & 8,000 & 250 \\
Combination Vessel & 7,000 & \\
Passenger Ship & 3,000 & \\
\hline
\end{tabular}

\section{Weaknesses in existing ballast water treatment systems}

Previously, ballast water exchange outside coastal waters has been the most commonly used method of reducing the risk of transfer of invasive organisms by repeatedly flushing the tanks and keeping appropriate records. The guiding principle has been that inshore/coastal organisms should be less likely to survive and thrive in the ocean. A number of different ballast water treatment systems are available, but only a very small number are currently approved and even these technologies have distinct limitations. Conventional ballast water treatment systems usually include filtration to remove larger organisms and detritus, but they can be insufficient especially when used to treat very large pumped water flows:

I. Susceptibility of UV systems to scaling and biofilm formation - UV systems require frequent cleaning to maintain performance. UV systems generally inactivate organisms and do not give any residual biocidal activity within the ballast water tanks thereby leaving the potential for regrowth of organisms, which requires retreatment during deballasting.

II. Vulnerability to organic loadings and corrosion - dosing with oxidizing agents (ozone, sodium hypochlorite, chlorine dioxide, etc.) for biological control are affected by organic loadings/chemical oxidation demand and promote corrosion.

III. Strict limitations on discharge of water containing chlorine - not possible to re-dose during discharge, because strict limits in the permitted concentration of freely available chlorine in water discharged to the marine environment, which arise from dosing with chlorine-based agents.

IV. Larger volume of chemicals required means higher costs for treatment - the larger the volumes of water to be treated effectively at very high pump rates means the more chemicals that must be dosed. In turn, this translates into larger quantities of chemicals that are carried/generated and the higher the cost of treatment. 
V. Larger vessels require more nitrogen gas - inert gas (nitrogen) displacement of dissolved oxygen in the ballast water requires a period of time to kill viable aerobic organisms and the larger the vessel, the larger the ballast tanks and consequently larger volumes of nitrogen gas are required for oxygen displacement. This requires larger nitrogen storage capacity.

VI. More energy and space are required - direct electrochemical treatment requires a minimum contact time in the cells to be effective, therefore larger/more cells are required with increased energy consumption and space requirements.

VII. Increased costs of retrofitting and reduced cargo capacity - the larger the required size of treatment system, the more the system encroaches into internal vessel space, increasing time and costs for retrofitting and reducing cargo capacity.

\section{Hydrodynamic cavitation}

Hydrodynamic cavitation occurs when a flowing liquid, (water) is subjected to rapid changes of pressure. Micro-vapour bubbles form in lower pressure regions of the liquid/water and when these vapour bubbles enter regions of higher pressure, they collapse adiabatically into remnant clouds of much smaller vapour bubbles releasing significant amounts of energy and producing shock waves, causing:

\section{Figure 1. Illustration}

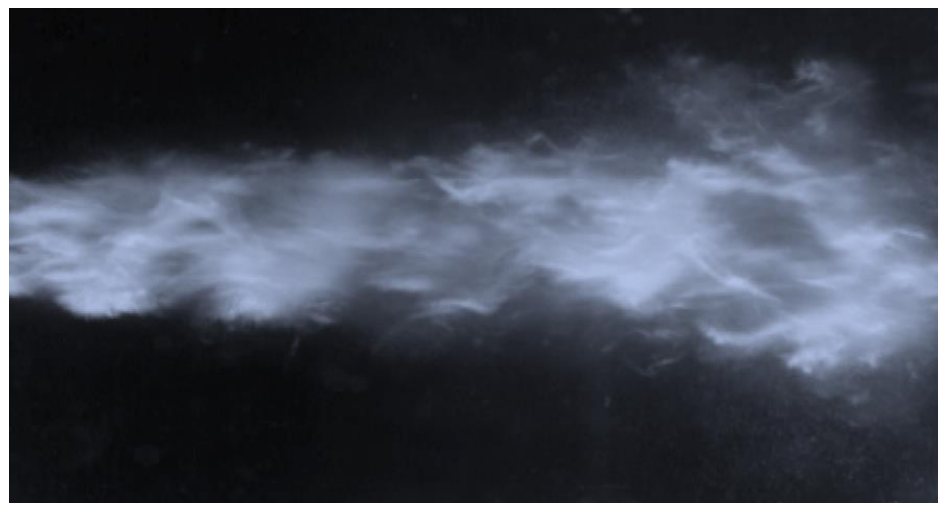

I. Substantial release of energy at the liquid/vapour interfaces, raising localised temperatures to $5,000 \mathrm{~K}$, heating the liquid across a few bubble radii for several microseconds.

II. Asymmetric bubble collapse generates high velocity micro-jets of liquid of up to $3,000 \mathrm{~m} / \mathrm{s}$ on the side of bubbles opposite the suspended material/particulates, which penetrate through the bubble volume and impinge upon the surfaces of the suspended material/particulates.

III. Exerting localised pressures reaching $9.65 \mathrm{Mbar}$. In the immediate vicinity causes penetration of surfaces and localises removal of material.

IV. Producing violent, highly localised, large amplitude shock waves after the point of minimum bubble cavity volume during collapse, which cause impulsive loading of the surfaces of nearby particulates/solid materials, inducing substantial stresses that result in surface damage and dislodgement of material.

V. The extremely high localised temperatures and pressures cause some water molecules to dissociate into unstable reactive hydrogen ions and hydroxyl radicals: $\mathrm{H} 2 \mathrm{O}=\mathrm{H}++\mathrm{OH}-$, which are continuously generated. Some of these radicals also combine with water molecules to form hydrogen peroxide and other peroxygens. 
VI. The remnant cloud vapour bubbles collapse in turn and releasing more energy, reactive hydrogen ions, hydroxyl radicals, and producing shock waves. This creates impulse pressures some 2-3 times higher than when the initial micro-vapour bubble collapses and are therefore even more destructive than the initial bubble collapses.

\section{Real-world effects and uses of cavitation}

The effects of energy releases when micro-vapour bubbles and remnant bubble clouds collapse can be observed in many situations, e.g. damage to ships' propellers, pump impellers, valve gates, dam spillways, etc. The rapid removal of marine biofouling, paint and rust during hydroblasting for cleaning the hulls of ships and the removal of the last sinews of meat/tissue from bones for use in processed/fast food production.

Cavitation is actually used by some marine life to stun/kill prey: the pistol shrimp snaps a specialised claw to create cavitation to stun/kill its prey (small fish) and one variety of mantis shrimp uses cavitation to stun its shellfish prey, break open their shells and kill them.

Adult dolphins and tuna, despite physical strength, are restricted in speed of swimming due to the formation and collapse of hydrodynamic cavitation micro-vapour bubbles at the trailing surfaces/edges of their tails and fins if they attempt to move them too quickly through the water causing damage.

\section{Figure 2. Illustration of cavitation}

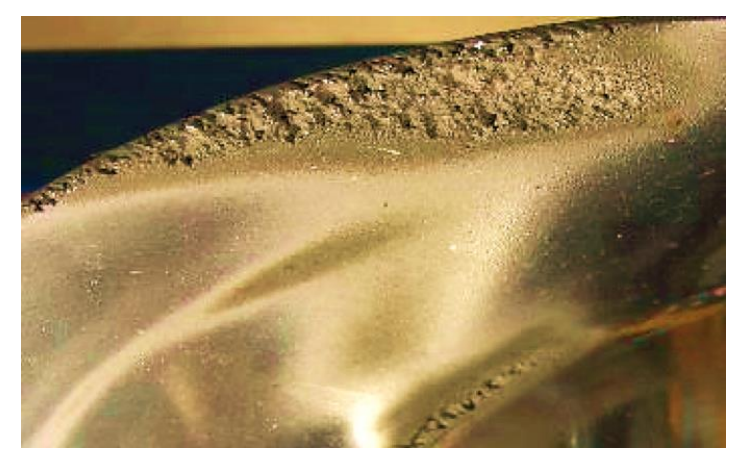

\section{Hydrodynamic cavitation for ballast water treatment}

Building upon its experience utilising hydrodynamic cavitation technology for other applications, Global Advantech Resources has determined some designs of hydrodynamic cavitation systems are effective for ballast water treatment (patent pending). Global Advantech Resources' design harnesses the significant energy releases, microjets, shock waves, hydroxyl radicals and peroxygens produced by the collapse of the micro-vapour bubbles and the remnant bubble clouds to destroy larvae, dinoflagellates and other organisms, eggs, bacteria, spores, etc., in pumped water flows. The effects upon the organisms of these combined, simultaneous energy releases, shockwaves and radical/ peroxygen production can be summarised as follows:

I. The micro-jets formed when the micro-vapour bubbles/remnant bubbles collapse penetrate cell walls allowing the cell contents to leak out. This results in cell death, destroying single cell organisms including planktonic bacteria, dinoflagellates and causing fatal damage to the tissues of multicellular organisms.

II. The shock waves and resulting shear forces impart substantial stress on cell walls of single and small multicellular organisms causing rupture and cell death and killing larger organisms, such as larvae.

III. The substantial heating effects are enough to kill single and small multicellular organisms within a few bubble radii. 
IV. The hydrogen ions and hydroxyl radicals denature and destroy proteins in cell walls, damaging and killing single and multicellular organisms and hydrogen peroxide and other peroxygens that are continuously produced are also highly biocidal.

\section{Figure 3. Micro-vapour bubbles}

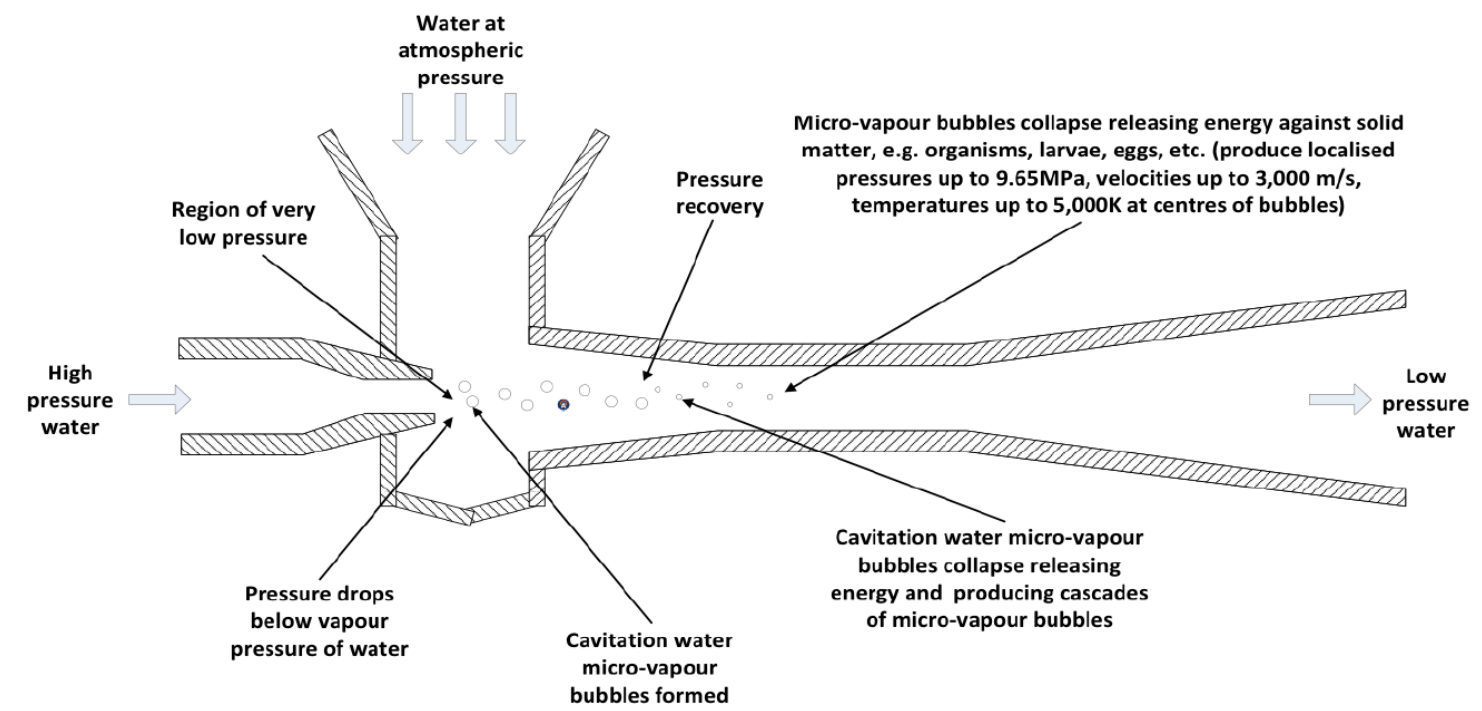

\section{Hydrodynamic cavitation ballast water treatment system design}

Important design features for hydrodynamic cavitation ballast water treatment systems include:

I. Reduced energy consumption and cargo space encroachment - utilisation of existing ballast water pumps to drive hydrodynamic cavitation generators, minimising additional energy (fuel) consumption and reduces impact/encroachment of treatment system upon valuable cargo capacity.

II. Fully scalable according to vessel size - system treatment capacity is scalable for any vessel size from the smallest to the largest - more hydrodynamic cavitation generators are connected in parallel via manifolds.

III. Design ensures maximum treatment effectiveness - optimisation of hydrodynamic cavitation generator design to maximise micro-vapour bubble generation at lower pump pressures (10-15 bar), re-mix treated water into micro-vapour bubble streams and maximise micro-vapour bubble/remnant bubble cloud interactions with organisms, larvae, etc., in the water to ensure maximum treatment effectiveness.

IV. Continuity of treatment - installation of multiple smaller hydrodynamic cavitation generators ensures redundancy in the event of blockage or damage to any individual generator allowing continuity of treatment.

V. Installation directly into ballast water tanks - option to install the hydrodynamic cavitation generators directly into ballast water tanks, in order to minimise space and overcome the problem of volumes of ballast water remaining at the bottom of the tanks after pump out and serve as a reservoir for the survival/regrowth of organisms, through treatment of water in the tanks by re-mixing it into the micro-vapour bubble streams/remnant bubble clouds. 
VI. Improved Ballast Water Management - improved ballast water management may be implemented with the treatment of water on intake and then retreatment during voyages, moving water between tanks through one or more treatment systems under computer control to ensure the stability and trim of the vessel are maintained at all times. This ensures that no "dead" volumes of water remain where organisms can survive and regrow.

Figure 4: System design

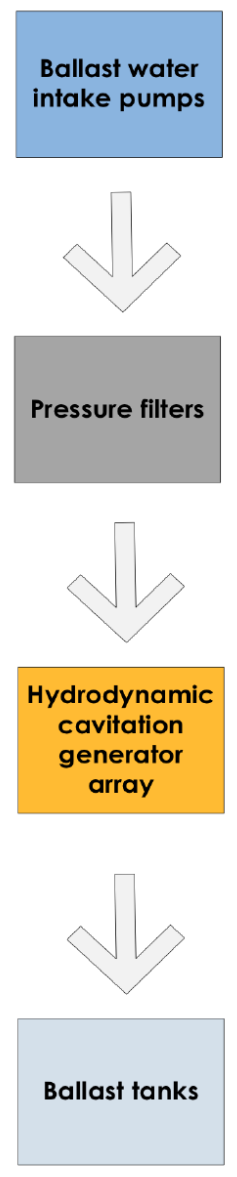

\section{Advantages to the installation of hydrodynamic cavitation systems for ballast water treatment}

In addition to the benefits outlined with the design features above, there are other important benefits:

I. No chemical stocks or electrochemical generator - efficient treatment avoids the need to carry large stocks of biocide chemicals or large power consuming electrochemical oxidant generators on board, saving space and costs.

II. Fewer corrosion problems - corrosion issues are much reduced compared with dosing of chemical oxidants as biocides, which directly promote corrosion of steel and other metals.

III. Minimal maintenance requirement. 
IV. Compatible with oxidant biocide dosing if required by authorities - may be utilised in conjunction with oxidant biocide dosing (but at much lower doses rates than when used as primary biological control) to further increase biocidal activity by their breakdown to release reactive radicals by the aggressive environment within hydrodynamic cavitation generators.

V. Installation time in dry dock and costs are minimised - hydrodynamic cavitation generators are modular and a number of relatively small generators are installed in parallel to make treatment units of the required capacities and large openings are not cut into the superstructure for access to facilitate the installation of the system.

\section{Conclusion}

Hydrodynamic cavitation generation offers substantial advantages and benefits for ballast water treatment, which cannot be overlooked given the pressing need for vessel owners to install treatment systems:

- Modular, scalable design.

- Effective and cost efficient for installation and use.

- Minimum loss of cargo space, since the hydrodynamic cavitation generators may be installed directly into existing ballast water tanks.

- No requirement for storage/generation of chemicals - low failure risk and no threat to the natural environment.

- Minimal maintenance requirement, easy replacement of damaged modules.

- Minimal additional energy consumption for treatment, leading to lower fuel costs

Global Advantech Resources intends to build and submit system designs for testing and approval by regulatory authorities for on board installation and use during this current year. 